\title{
A Fixed Point Theorem for Three Pairs of Mappings Satisfying Contractive Condition of Integral Type in Dislocated Metric Space
}

\author{
Mujeeb Ur Rahman and Muhammad Sarwar \\ Department of Mathematics, University of Malakand, Chakdara, Lower Dir District, Khyber Pakhtunkhwa 18800, Pakistan \\ Correspondence should be addressed to Muhammad Sarwar; sarwarswati@gmail.com
}

Received 5 September 2014; Revised 12 December 2014; Accepted 12 December 2014; Published 28 December 2014

Academic Editor: Lingju Kong

Copyright (C) 2014 M. Ur Rahman and M. Sarwar. This is an open access article distributed under the Creative Commons Attribution License, which permits unrestricted use, distribution, and reproduction in any medium, provided the original work is properly cited.

The aim of this paper is to study a common fixed point theorem for three pairs of self-mappings satisfying a contractive condition of integral type in the setting of dislocated metric space. We notice that our established theorem generalizes the main result of Branciari (2002) in the context of dislocated metric space.

\section{Introduction}

In 1922, Banach proved a fixed point theorem for contraction mapping in complete metric space. Banach contraction theorem is one of the pivotal results of functional analysis. It has many applications in various fields of mathematics such as differential equations and integral equations. There are many generalizations of Banach contraction theorem in the literature. One of the most interesting generalizations of it is that of Branciari [1]. Branciari [1] proved a fixed point theorem for a single map satisfying an analogue of Banach contraction principle of integral type. Furthermore, authors in $[2,3]$ proved fixed point theorems satisfying more general contractive conditions of integral type in metric space.

The notion of dislocated metric $(d$-metric) space was introduced by Hitzler and Seda in $[4,5]$. This notion plays a vital role in logic programming semantics, electronic engineering, and computer science [5]. Compatible mappings were introduced by Jungck in [6]. The same author in $[7,8]$ generalized the concept of compatible mappings and introduced the concept of weakly compatible mappings. Since then several papers have been published containing fixed point results for weakly compatible maps in dislocated metric space (see [9-11]). Moreover, Al-Thagafi and Shahzad [12] initiated the concept of occasionally weakly compatible (owc) mappings. In the present days occasionally weakly compatible mappings become an interesting research topic in the field of metric fixed point theory.

In this paper, we have proved a common fixed point theorem for six self-mappings satisfying a new type of contractive condition of integral type using the idea of weakly compatible and commuting maps in the frame work of dislocated metric space.

\section{Preliminaries}

Throughout this paper $\mathbb{R}^{+}$will represent the set of nonnegative real numbers.

Definition 1 (see [5]). Let $X$ be a nonempty set and $d: X \times$ $X \rightarrow \mathbb{R}^{+}$a function satisfying the following conditions:

$$
\begin{aligned}
& \left(d_{1}\right) d(x, x)=0 ; \\
& \left(d_{2}\right) d(x, y)=d(y, x)=0 \text { implies } x=y ; \\
& \left(d_{3}\right) d(x, y)=d(y, x) ; \\
& \left(d_{4}\right) d(x, y) \leq d(x, z)+d(z, y) \text { for all } x, y, z \in X .
\end{aligned}
$$

If $d$ satisfies the conditions from $d_{1}$ to $d_{4}$ then it is called metric on $X$; if $d$ satisfies conditions $d_{2}$ to $d_{4}$ then it is called dislocated metric ( $d$-metric) on $X$. The pair $(X, d)$ is called dislocated metric space. 
Clearly every metric space is a dislocated metric space but the converse is not necessarily true as clear from the following example.

Example 2. Let $X=\mathbb{R}^{+}$define the distance function $d: X \times$ $X \rightarrow \mathbb{R}^{+}$by

$$
d(x, y)=x+y \quad \forall x, y \in X
$$

Clearly $(X, d)$ is a dislocated metric space but not a metric space.

The following definitions are required in the sequel which can be found in [5].

Definition 3. A sequence $\left\{x_{n}\right\}$ in $d$-metric space $(X, d)$ is called Cauchy sequence if for $\epsilon>0$ there exists a positive integer $n_{0} \in N$ such that, for $m, n \geq n_{0}$, one has

$$
d\left(x_{m}, x_{n}\right)<\epsilon .
$$

Definition 4. A sequence $\left\{x_{n}\right\}$ in dislocated metric space $(X, d)$ is called dislocated convergent ( $d$-convergent) if

$$
\lim _{n \rightarrow \infty} d\left(x_{n}, x\right)=\lim _{n \rightarrow \infty} d\left(x, x_{n}\right)=x
$$

In such a case $x$ is called the dislocated limit ( $d$-limit) of the sequence $\left\{x_{n}\right\}$.

Definition 5. A $d$-metric space $(X, d)$ is said to be complete if every Cauchy sequence in $X$ converges to a point in $X$.

Definition 6. Let $(X, d)$ be a $d$-metric space. A mapping $T$ : $X \rightarrow X$ is called contraction if there exist $0 \leq \alpha<1$ such that

$$
d(T x, T y) \leq \alpha \cdot d(x, y) \quad \forall x, y \in X .
$$

Lemma 7 (see [5]). Limit in d-metric space is unique.

Theorem 8 (see [5]). Let $(X, d)$ be a complete $d$-metric space $T: X \rightarrow X$ a contraction. Then $T$ has a unique fixed point.

Definition 9 (see [9]). Let $S$ and $T$ be two self-mappings on a nonempty set $X$; then

(1) any point $x \in X$ is said to be fixed point of $T$ if $T x=x$;

(2) any point $x \in X$ is called coincidence point of $S$ and $T$ if $S x=T x$ and one calls $u=S x=T x$ a point of coincidence of $S$ and $T$;

(3) a point $x \in X$ is called common fixed point of $S$ and $T$ if $S x=T x=x$.

Definition 10 (see [13]). Let $S$ and $T$ be two mappings on a nonempty set $X$. Then $S$ and $T$ are said to be a commuting pair if

$$
S T x=T S x \quad \forall x \in X .
$$

In [6] Jungck introduced the concept of compatible mappings which generalize the concept of commuting maps.
Definition 11. Let $S$ and $T$ be self-mappings on a nonempty set $X$. Then $S$ and $T$ are said to be compatible mappings if

$$
\lim _{n \rightarrow \infty} d\left(S T x_{n} ; T S x_{n}\right)=0
$$

whenever there exists a sequence $\left\{x_{n}\right\}$ in $X$ such that

$$
\lim _{n \rightarrow \infty} S x_{n}=\lim _{n \rightarrow \infty} T x_{n}=t \quad \text { for some } t \in X .
$$

Clearly compatible mappings commute at their coincidence sequence.

Jungck in [7] further generalized the concept of compatible maps as follows.

Definition 12 (see [7]). Let $S$ and $T$ be two self-mappings on a nonempty set $X$. Then $S$ and $T$ are said to be weakly compatible if they commute at all of their coincidence points; that is, $S u=T u$ for some $u \in X$ and then $S T u=T S u$.

Obviously compatible mappings are weakly compatible but the converse is not true.

Example 13. Let $X=R$, with the usual metric $d$. Define $S, T$ : $R \rightarrow R$ by

$$
S x=[x], \quad T x= \begin{cases}-2 & \text { if } x \leq 0 \\ 0 & \text { if } 0<x<2 \\ 2 & \text { if } x \geq 2,\end{cases}
$$

where $[x]$ denotes the integral part of $x$. In the above if $\left\{x_{n}\right\}=$ $1 / n$, then $S$ and $T$ are not compatible but they are weakly compatible as they commute at their coincidence points; that is, $x= \pm 2$.

The following concept, introduced by Al-Thagafi and Shahzad in [12], is a proper generalization of nontrivial weakly compatible maps which do have a coincidence point.

Definition 14. Let $S$ and $T$ be two self-mappings on a nonempty set $X$. Then $S$ and $T$ are said to be occasionally weakly compatible (owc) if there exists at least one coincidence point of $S$ and $T$ at which they commute; that is, STx $=$ $T S x$ implies that $S x=T x$ for any coincidence point $x$.

The following example shows that the weakly compatible maps form a proper subclass of occasionally weakly compatible maps.

Example 15. Let $X=[0, \infty)$ with the usual metric. Define $S, T: X \rightarrow X$ by $S x=2 x$ and $T x=x^{2}$ for all $x \in X$. Then $C(S, T)=\{0,2\}$ and $S(T(0))=T(S(0))$ but $S(T(2)) \neq T(S(2))$. Therefore $(S, T)$ are an owc pair but not weakly compatible.

Lemma 16 (see [14]). Let $S, T$, and $f$ be self-mappings on a nonempty set $X$ with $S, T$, and $f$ having a unique point of coincidence in $X$. If $(S, f)$ and $(T, f)$ are weakly compatible. Then $S, T$, and $f$ have a unique common fixed point.

In 2002, Branciari [1] proved the following theorem which is one of the interesting generalizations of Banach contraction principle. 
Theorem 17. Let $(X, d)$ be a complete metric space $\alpha \in(0,1)$. Let $T: X \rightarrow X$ be a mapping such that for all $x, y \in X$ the following condition holds:

$$
\int_{0}^{d(T x, T y)} \rho(t) d t \leq \alpha \cdot \int_{0}^{d(x, y)} \rho(t) d t,
$$

where $\rho: \mathbb{R}^{+} \rightarrow \mathbb{R}^{+}$is a Lebesgue integrable mapping which is summable on each compact subset of $\mathbb{R}^{+}$, nonnegative and such that for any $s>0 \int_{0}^{s} \rho(t) d t>0$. Then $T$ has a unique fixed point.

Definition 18 (see [15]). A map $\varphi: \mathbb{R}_{+} \rightarrow \mathbb{R}_{+}$is called comparison function if it satisfies the following:

(1) $\varphi$ is monotonic increasing.

(2) The sequence $\left\{\varphi^{n}(t)\right\}_{n=0}^{\infty}$ converges to zero for all $t \in$ $\mathbb{R}_{+}$where $\varphi^{n}$ stands for $n$th iterate of $\varphi$.

If $\varphi$ satisfies

(3) $\sum_{k=0}^{\infty} \varphi^{k}(t)$ which converge for all $t \in \mathbb{R}_{+}$, then $\varphi$ is called $(c)$-comparison function.

Thus every comparison function is $c$-comparison function. A prototype example for comparison function is

$$
\varphi(t)=\alpha t \quad t \in \mathbb{R}_{+} 0 \leq \alpha<1 .
$$

Some more examples and properties of comparison and $c$-comparison function can be found in [15].

\section{Main Result}

Theorem 19. Let $(X, d)$ be a complete $d$-metric space. Let $A, B, S, T, P, Q: X \rightarrow X$ be self-mappings satisfying the following conditions:

(1) $P(X) \subseteq S T(X), Q(X) \subseteq A B(X)$;

(2) the pairs $(P, A B)$ and $(Q, S T)$ are weakly compatible mappings;

(3) $\int_{0}^{d(P x, \mathrm{Q} y)} \rho(t) d t \leq \phi \int_{0}^{M(x, y)} \rho(t) d t$;

where $M(x, y)=\min \{d(A B x, S T y), d(P x, A B x), d(Q y, S T y)\}$ for all $x, y \in X$ and $\phi: \mathbb{R}_{+} \rightarrow \mathbb{R}_{+}$is a (c)-comparison function with $\rho: \mathbb{R}_{+} \rightarrow \mathbb{R}_{+}$being a Lebesgue integrable mapping which is summable on each compact subset of $\mathbb{R}_{+}$, nonnegative and such that for any $s>0 \int_{0}^{s} \rho(t) d t>0$. Then $A B, S T, P$, and $Q$ have a unique common fixed point. Moreover, if $(A, B)$ and $(S, T)$ are commuting pairs, then $A, B, P, Q, S$, and $T$ have a unique common fixed point.

Proof. Using condition (1) we construct the Jungck sequence $\left\{y_{n}\right\}$ by the rule

$$
\begin{gathered}
y_{2 n}=S T x_{2 n+1}=P x_{2 n}, \\
y_{2 n+1}=A B x_{2 n+2}=Q x_{2 n+1} \quad \text { for } n=0,1,2, \ldots
\end{gathered}
$$

Now using (3) we have

$$
\begin{aligned}
& \int_{0}^{d\left(y_{2 n}, y_{2 n+1}\right)} \rho(t) d t \\
& \quad \int_{0}^{d\left(P x_{2 n}, \mathrm{Q} x_{2 n+1}\right)} \rho(t) d t \leq \phi \int_{0}^{M(x, y)} \rho(t) d t \\
& \leq \phi \int_{0}^{\min \left\{d\left(A B x_{2 n}, S T x_{2 n+1}\right), d\left(P x_{2 n}, A B x_{2 n}\right), d\left(\mathrm{Qx}_{2 n+1}, S T x_{2 n+1}\right)\right\}} \rho(t) d t .
\end{aligned}
$$

Using the defined construction of the sequence we have

$$
\begin{gathered}
=\phi \int_{0}^{\min \left\{d\left(y_{2 n-1}, y_{2 n}\right), d\left(y_{2 n}, y_{2 n-1}\right), d\left(y_{2 n+1}, y_{2 n}\right)\right\}} \rho(t) d t \\
=\phi \int_{0}^{\min \left\{d\left(y_{2 n-1}, y_{2 n}\right), d\left(y_{2 n+1}, y_{2 n}\right)\right\}} \rho(t) d t .
\end{gathered}
$$

Finally we have

$$
\int_{0}^{d\left(y_{2 n}, y_{2 n+1}\right)} \rho(t) d t \leq \phi \int_{0}^{\min \left\{d\left(y_{2 n-1}, y_{2 n}\right), d\left(y_{2 n}, y_{2 n+1}\right)\right\}} \rho(t) d t .
$$

If $\min \left\{d\left(y_{2 n-1}, y_{2 n}\right), d\left(y_{2 n}, y_{2 n+1}\right)\right\}=d\left(y_{2 n}, y_{2 n+1}\right)$, then we have

$$
\begin{aligned}
\int_{0}^{d\left(y_{2 n}, y_{2 n+1}\right)} \rho(t) d t & \leq \phi \int_{0}^{d\left(y_{2 n}, y_{2 n+1}\right)} \rho(t) d t \\
& <\int_{0}^{d\left(y_{2 n}, y_{2 n+1}\right)} \rho(t) d t
\end{aligned}
$$

which is a contradiction. Therefore $\min \left\{d\left(y_{2 n-1}, y_{2 n}\right), d\left(y_{2 n}\right.\right.$, $\left.\left.y_{2 n+1}\right)\right\}=d\left(y_{2 n-1}, y_{2 n}\right)$; hence we have

$$
\int_{0}^{d\left(y_{2 n}, y_{2 n+1}\right)} \rho(t) d t \leq \phi \int_{0}^{d\left(y_{2 n-1}, y_{2 n}\right)} \rho(t) d t .
$$

Also

$$
\int_{0}^{d\left(y_{2 n-1}, y_{2 n}\right)} \rho(t) d t \leq \phi^{2} \int_{0}^{d\left(y_{2 n-2}, y_{2 n-1}\right)} \rho(t) d t .
$$

Similarly proceeding we have

$$
\int_{0}^{d\left(y_{n}, y_{n+1}\right)} \rho(t) d t \leq \phi^{n} \int_{0}^{d\left(y_{0}, y_{1}\right)} \rho(t) d t .
$$

Since $\phi$ is $(c)$-comparison function so by taking limit $n \rightarrow \infty$ implies $\phi^{n} \rightarrow 0$. Therefore

$$
\lim _{n \rightarrow \infty} \int_{0}^{d\left(y_{n}, y_{n+1}\right)} \rho(t) d t=0 \Longrightarrow \lim _{n \rightarrow \infty} d\left(y_{n}, y_{n+1}\right)=0 .
$$

Hence $\left\{y_{n}\right\}$ is a Cauchy sequence in complete $d$-metric space. So there must exist $u \in X$ such that

$$
\lim _{n \rightarrow \infty} y_{n}=u
$$


Also the subsequences $\left\{y_{2 n}\right\}$ and $\left\{y_{2 n+1}\right\}$ converge to $u$. So $\left\{P x_{2 n}\right\},\left\{Q x_{2 n+1}\right\},\left\{S T x_{2 n+1}\right\}$, and $\left\{A B x_{2 n+2}\right\}$ converge to $u$. Using (1) since $P(X) \subseteq S T(X)$ so there must exist $z \in X$ such that $S T z=u$. Now using (3) we have

$$
\begin{aligned}
& \int_{0}^{d(u, \mathrm{Q} z)} \rho(t) d t \\
& \quad=\int_{0}^{d\left(P x_{2 n}, \mathrm{Q} z\right)} \rho(t) d t \\
& \quad \leq \phi \int_{0}^{\min \left\{d\left(A B x_{2 n}, S T z\right), d\left(P x_{2 n}, A B x_{2 n}\right), d(\mathrm{Q} z, S T z)\right\}} \rho(t) d t \\
& \quad \leq \phi \int_{0}^{\min \left\{d\left(y_{2 n-1}, u\right), d\left(y_{2 n}, y_{2 n-1}\right), d(\mathrm{Q} z, u)\right\}} \rho(t) d t .
\end{aligned}
$$

Taking limit $n \rightarrow \infty$ we get the following inequality:

$$
\int_{0}^{d(u, \mathrm{Q} z)} \rho(t) d t \leq \phi \int_{0}^{\min \{d(u, u), d(u, u), d(\mathrm{Q} z, u)\}} \rho(t) d t .
$$

Since $d(u, u) \leq d(u, Q z)+d(Q z, u)$, therefore $\min \{d(u, u)$, $d(Q z, u)\}=d(Q z, u)=d(u, Q z)$;

$$
\int_{0}^{d(u, \mathrm{Q} z)} \rho(t) d t \leq \phi \int_{0}^{d(u, \mathrm{Q} z)} \rho(t) d t<\int_{0}^{d(u, \mathrm{Q} z)} \rho(t) d t
$$

which is a contradiction; therefore $d(u, Q z)=0 \Rightarrow Q z=u$. Hence $S T z=Q z=u$.

Also since $Q(X) \subseteq A B(X)$ so there must exist $w \in X$ such that $A B w=u$. Again using (3) we have

$$
\begin{aligned}
& \int_{0}^{d(P w, u)} \rho(t) d t \\
& \quad=\int_{0}^{d\left(P w, \mathrm{Q} x_{2 n+1}\right)} \rho(t) d t \\
& \quad \leq \phi \int_{0}^{\min \left\{d\left(A B w, S T x_{2 n+1}\right), d(P w, A B w), d\left(\mathrm{Q} x_{2 n+1}, S T x_{2 n}\right)\right\}} \rho(t) d t \\
& \quad \leq \phi \int_{0}^{\min \left\{d\left(u, y_{2 n}\right), d(P w, u), d\left(y_{2 n+1}, y_{2 n}\right)\right\}} \rho(t) d t .
\end{aligned}
$$

Taking limit $n \rightarrow \infty$ we have

$$
\int_{0}^{d(P w, u)} \rho(t) d t \leq \phi \int_{0}^{\min \{d(u, u), d(P w, u), d(u, u)\}} \rho(t) d t .
$$

Since $\min \{d(u, u), d(P w, u), d(u, u)\}=d(P w, u)$, so

$$
\int_{0}^{d(P w, u)} \rho(t) d t \leq \phi \int_{0}^{d(P w, u)} \rho(t) d t<\int_{0}^{d(P w, u)} \rho(t) d t
$$

which is again a contradiction. Therefore $d(P w, u)=0 \Rightarrow$ $P w=u$. Hence $S T z=Q z=P w=A B w=u$. Thus $u$ is the point of coincidence of $P, Q, S T$, and $A B$. Now we have to show that the point of coincidence of $P, Q, S T$, and $A B$ is unique.
Let $u^{\prime} \neq v^{\prime}$ be two distinct points of coincidence of $P, Q, S T$, and $A B$. Then $S T z^{\prime}=Q z^{\prime}=P w^{\prime}=A B w^{\prime}=u^{\prime}$. Consider

$$
\int_{0}^{d\left(u, u^{\prime}\right)} \rho(t) d t=\int_{0}^{d\left(P w, Q z^{\prime}\right)} \rho(t) d t .
$$

Using (3) we have

$$
\begin{aligned}
& \int_{0}^{d\left(u, u^{\prime}\right)} \rho(t) d t \\
& \quad \leq \phi \int_{0}^{\min \left\{d\left(A B w, S T z^{\prime}\right), d(P w, A B w), d\left(\mathrm{Q}^{\prime}, S T z^{\prime}\right)\right\}} \rho(t) d t \\
& \quad \leq \phi \int_{0}^{\min \left\{d\left(u, u^{\prime}\right), d(u, u), d\left(u^{\prime}, u^{\prime}\right)\right\}} \rho(t) d t .
\end{aligned}
$$

Since $d(u, u) \leq d\left(u, u^{\prime}\right)+d\left(u^{\prime}, u\right)$ implies $d(u, u) \leq 2 d\left(u, u^{\prime}\right)$, therefore $\min \left\{d\left(u, u^{\prime}\right), 2 d\left(u, u^{\prime}\right)\right\}=d\left(u, u^{\prime}\right)$ :

$$
\int_{0}^{d\left(u, u^{\prime}\right)} \rho(t) d t \leq \phi \int_{0}^{d\left(u, u^{\prime}\right)} \rho(t) d t<\int_{0}^{d\left(u, u^{\prime}\right)} \rho(t) d t
$$

which is a contradiction; therefore $d\left(u, u^{\prime}\right)=0 \Rightarrow u=u^{\prime}$. Hence point of coincidence of $P, Q, S T$, and $A B$ is unique. Also since $(P, A b)$ and $(Q, S t)$ are weakly compatible so by Lemma $16 P, Q, S T$, and $A B$ have a unique common fixed point in $X$. That is, $P u=Q u=S T u=A B u=u$.

Now if $(A, B)$ and $(S, T)$ are commuting pairs then

$$
A u=A(A B u)=A(B A u)=A B(A u)
$$

which implies that $A u$ is the fixed point of $A B$ but as proved above fixed point of $A B$ is unique. Therefore $A u=u$ which implies that $u$ is the fixed point of $A$. Also

$$
B u=B(A B u)=B A(B u)=A B(B u) .
$$

Using the similar argument as above we can get that $B u=u$. Thus $u$ is the fixed point of $B$. Similarly one can easily show that $S u=u$ and $T u=u$. Hence $A, B, P, Q, S$, and $T$ have a common fixed point in $X$.

Uniqueness. Let $u \neq v$ be two distinct common fixed points of $A, B, P, Q, S$, and $T$; then consider

$$
\begin{gathered}
\int_{0}^{d(u, v)} \rho(t) d t=\int_{0}^{d(P u, Q v)} \rho(t) d t \leq \phi \int_{0}^{M(x, y)} \rho(t) d t, \\
M(x, y)=\min \{d(A B u, S T v), d(P u, A B u), d(Q v, S T v)\}, \\
M(x, y)=\min \{d(u, v), d(u, u), d(v, v)\} .
\end{gathered}
$$

Since

$$
d(u, u) \leq d(u, v)+d(v, u)
$$

then

$$
d(v, v) \leq d(v, u)+d(u, v) .
$$


Hence

$$
\begin{gathered}
\min \{d(u, v), 2 d(u, v)\}=d(u, v) \\
\int_{0}^{d(u, v)} \rho(t) d t \leq \phi \int_{0}^{d(u, v)} \rho(t) d t<\int_{0}^{d(u, v)} \rho(t) d t
\end{gathered}
$$

which is again a contradiction. Therefore $d(u, v)=0 \Rightarrow u=$ $v$. Thus common fixed point of $A, B, S, T, P$, and $Q$ is unique.

We deduce the following corollary from Theorem 19.

Corollary 20. In Theorem 19 if $\rho(t)=I$ and all other conditions of the above theorem hold, then again $A, B, S, T$, $P$, and $Q$ have a unique common fixed point.

Remarks. (i) Corollary 20 is the result of Chauhan and Utereja [16] for weakly compatible mappings.

(ii) Theorem 19 is a generalization of the main result of Branciari [1] in dislocated metric space.

Example 21. Let $X=[0,1]$ with dislocated metric on $X$ which is defined by

$$
d(x, y)=|x-y|+|x|+|y|
$$

for all $x, y \in X$. Define $A, B, S, T, P$, and $Q$ as

$$
\begin{array}{r}
P x=T x=\frac{x}{2}, \quad Q x=\frac{x}{4}, \quad A x=B x=S x=x \\
\forall x \in X .
\end{array}
$$

Satisfy all the conditions of Theorem 19 for $\phi(t)=t / 2 t \in \mathbb{R}_{+}$ having $x=0$ as the unique common fixed point of $A, B, S, T$, $P$, and $Q$.

\section{Conflict of Interests}

The authors declare that there is no conflict of interests regarding the publication of this paper.

\section{Acknowledgments}

The authors are grateful to the editor and anonymous reviewer for their careful reviews, valuable comments, and remarks to improve this paper.

\section{References}

[1] A. Branciari, "A fixed point theorem for mappings satisfying a general contractive condition of integral type," International Journal of Mathematics and Mathematical Sciences, vol. 29, no. 9, pp. 531-536, 2002.

[2] I. Altun, "Common fixed point theorem for maps satisfying a general contractive condition of integral type," Acta University Apulensis, vol. 22, pp. 195-206, 2010.

[3] U. C. Gairola and A. S. Rawat, "A fixed point theorem for two pair of maps satisfying a new contractive condition of integral type," International Mathematical Forum, vol. 4, no. 1-4, pp. 177183, 2009.
[4] P. Hitzler and A. K. Seda, "Dislocated topologies," Journal of Electrical Engineering, vol. 51, pp. 3-7, 2000.

[5] P. Hitzler, Generalized metrics and topology in logic programming semantics [Ph.D. thesis], National Univeristy of Ireland, University College Cork, Maynooth, Ireland, 2001.

[6] G. Jungck, "Compatible mappings and common fixed points," International Journal of Mathematics and Mathematical Sciences, vol. 9, no. 4, pp. 771-779, 1986.

[7] G. Jungck, "Fixed point for non-continous non-self mappings on non-metric space," Far East Journal of Mathematical Sciences, vol. 4, pp. 199-212, 1996.

[8] G. Jungck and B. E. Rhoades, "Fixed points for set valued functions without continuity," Indian Journal of Pure and Applied Mathematics, vol. 29, no. 3, pp. 227-238, 1998.

[9] P. S. Kumari, V. V. Kumar, and I. Rambhadra Sarma, "Common fixed point theorems on weakly compatible maps on dislocated metric spaces," Mathematical Sciences, vol. 6, pp. 1-5, 2012.

[10] K. Jha and D. Panthi, "A common fixed point theorem in dislocated metric space," Applied Mathematical Sciences, vol. 6, no. 89-92, pp. 4497-4503, 2012.

[11] K. P. Rao and P. R. Swamy, "A coincidence point theorem for four mappings in dislocated metric spaces," International Journal of Contemporary Mathematical Sciences, vol. 6, no. 3336, pp. 1675-1680, 2011.

[12] M. A. Al-Thagafi and N. Shahzad, "A note on occasionally weakly compatible maps," International Journal of Mathematical Analysis, vol. 3, no. 1-4, pp. 55-58, 2009.

[13] G. Jungck, "Commuting mappings and fixed points," The American Mathematical Monthly, vol. 83, no. 4, pp. 261-263, 1976.

[14] M. Azam and M. Arshad, "Common fixed points of generalized contractive maps in cone metric space," Bulltein of Iranian Mathematical Society, vol. 35, pp. 255-264, 2009.

[15] V. Berinde, "On the approximation of fixed points of weak contractive mappings," Carpathian Journal of Mathematics, vol. 19, no. 1, pp. 7-22, 2003.

[16] S. S. Chauhan and K. Utereja, "A common fixed point theorem in dislocated metric space," International Journal of Engineering and Innovative Technology, vol. 3, pp. 504-507, 2013. 


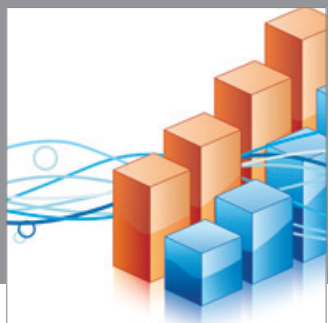

Advances in

Operations Research

mansans

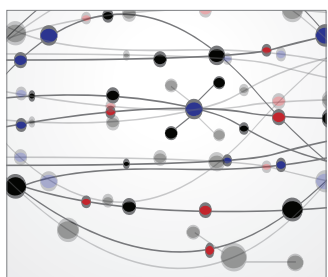

The Scientific World Journal
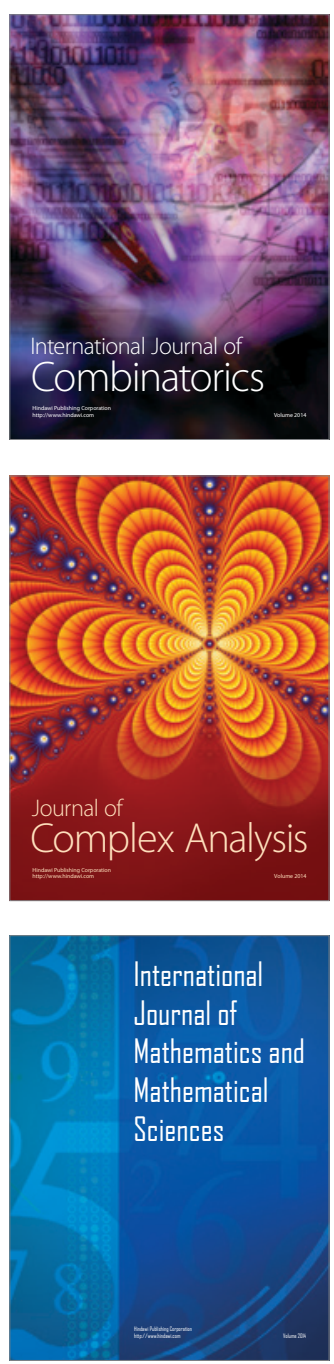
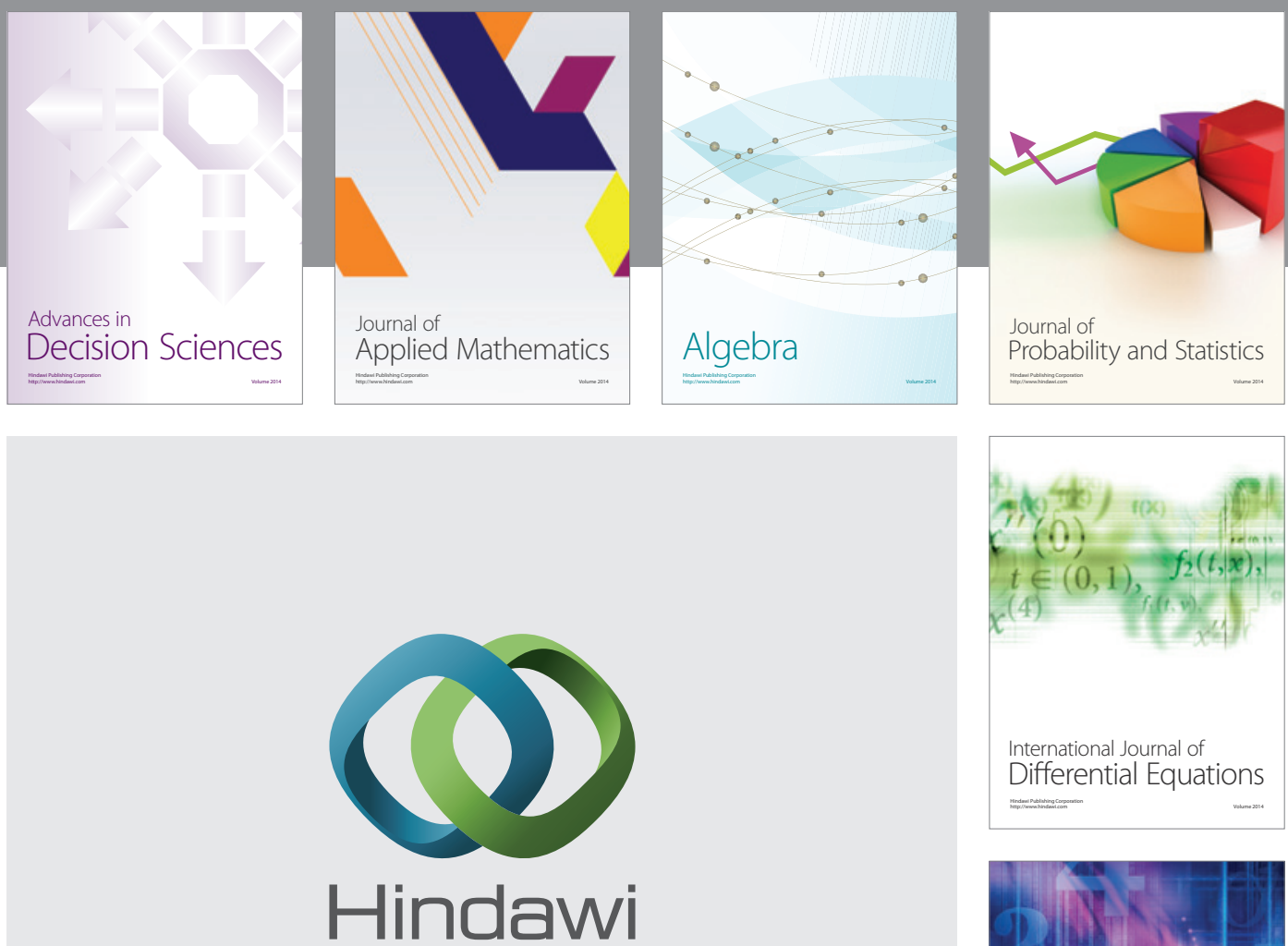

Submit your manuscripts at http://www.hindawi.com
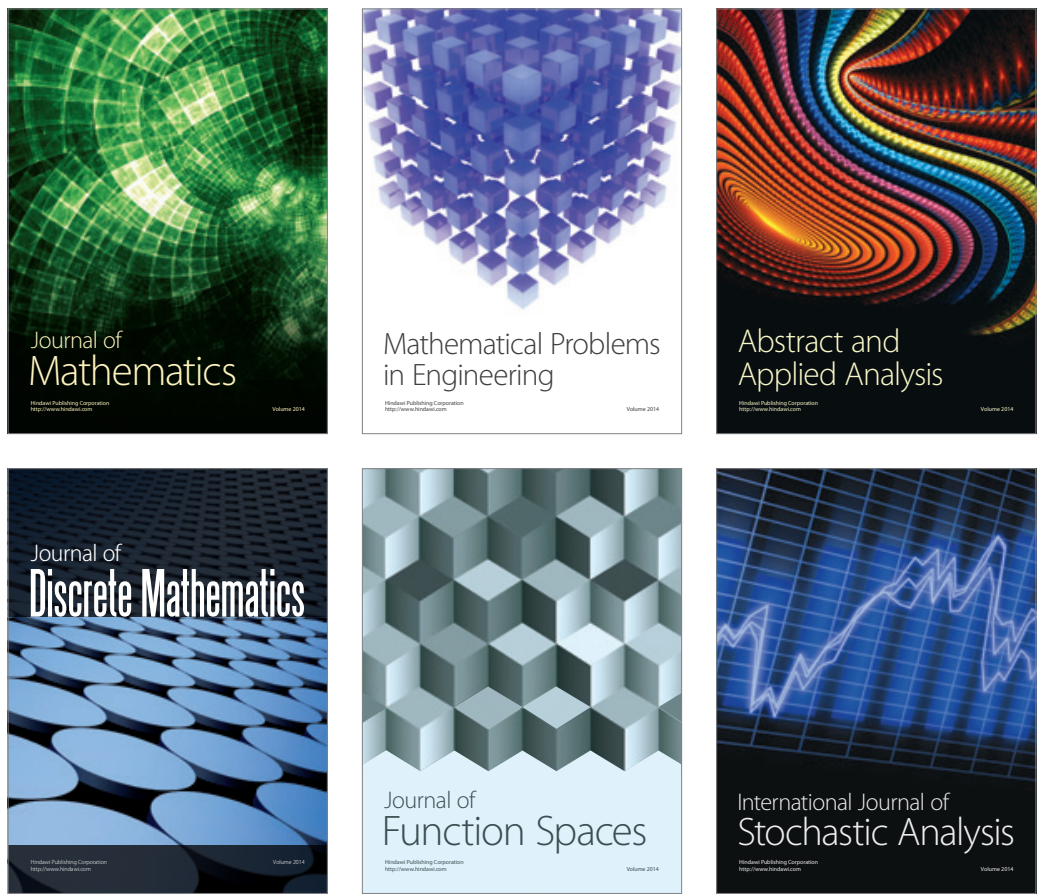

Journal of

Function Spaces

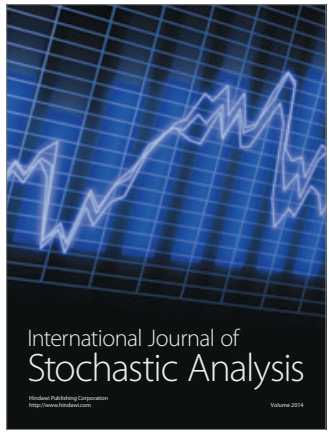

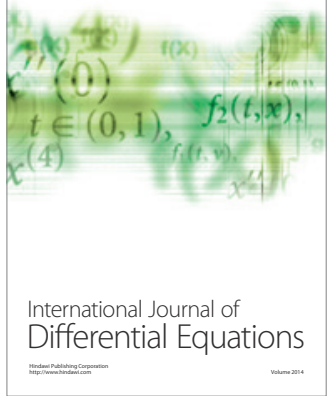
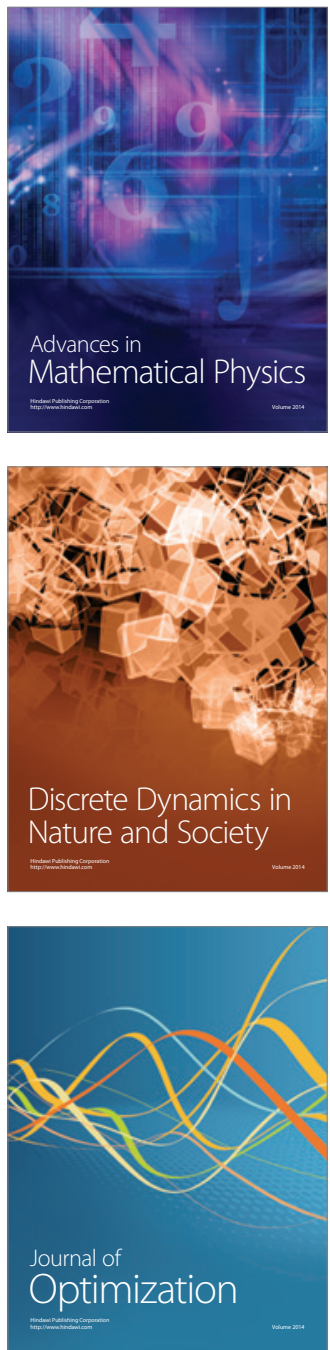